\title{
OPEN Publisher Correction: Floquet-state cooling
}

\section{Onno R. Diermann \& Martin Holthaus}

Correction to: Scientific Reports https://doi.org/10.1038/s41598-019-53877-w, published online 26 November 2019

This Article contains errors in the Reference section:

"12. Iadecola, T., Neupert, T. \& Chamon, C. Classification of the Floquet statistical distribution for time-periodic open systems. Phys. Rev. B 91, 144301 (2015).”

should read:

"12. Liu, D.E. Classification of the Floquet statistical distribution for time-periodic open systems. Phys. Rev. B 91, 144301 (2015)."

“13. Th. Iadecola, T., Neupert \& Chamon, C. Occupation of topological Floquet bands in open systems. Phys. Rev. B 91, 235133 (2015)."

should read:

“13. Iadecola, T., Neupert, T. \& Chamon, C. Occupation of topological Floquet bands in open systems. Phys. Rev. B 91, 235133 (2015).”

“15. Vajna, S., Horovitz, B., Dora, B. \& Zarand, G. Floquet theorem with open systems and its applications. Phys. Rev. A 93, 032121 (2016).”

should read:

“15. Dai, C.M., Shi, Z.C. \& Yi, X.X. Floquet theorem with open systems and its applications. Phys. Rev. A 93, 032121 (2016)"”

“16. Vajna, S., Horovitz, B., Doraand, B. \& Zarand, G. Floquet topological phases coupled to environments and the induced photocurrent. Phys. Rev. B 94, 115145 (2016).”

should read:

“16. Vajna, S., Horovitz, B., Dora, B. \& Zarand, G. Floquet topological phases coupled to environments and the induced photocurrent. Phys. Rev. B 94, 115145 (2016).”

(i) Open Access This article is licensed under a Creative Commons Attribution 4.0 International License, which permits use, sharing, adaptation, distribution and reproduction in any medium or format, as long as you give appropriate credit to the original author(s) and the source, provide a link to the Creative Commons license, and indicate if changes were made. The images or other third party material in this article are included in the article's Creative Commons license, unless indicated otherwise in a credit line to the material. If material is not included in the article's Creative Commons license and your intended use is not permitted by statutory regulation or exceeds the permitted use, you will need to obtain permission directly from the copyright holder. To view a copy of this license, visit http://creativecommons.org/licenses/by/4.0/.

(C) The Author(s) 2020 